Revista Signos
$2010 / 43$

Número Especial

Monográfico $\mathrm{N}^{\circ} 1$

$161-182$

\author{
Cláudia Lopes Nascimento Saito \\ Universidade Estadual Centro-Oeste \\ Brasil
}

\title{
0 gênero textual: Adaptação oficial de filme em quadrinhos
}

\begin{abstract}
Resumo: Com as mesmas características do seu gênero de origem -as histórias em quadrinhos-, a 'adaptação oficial de filme em quadrinhos' vem se destacando por apresentar a transposição das películas cinematográficas para suportes impressos como, por exemplo, os filmes de super-heróis tal como o Homem-Aranha II, corpus desta pesquisa. Tomando como aportes teóricos fundamentos da semiótica (Greimas \& Courtés, 1979), aliados ao interacionismo sociodiscursivo (Bronckart, 2003, 2006), esta pesquisa apresenta dados de análise e descrição do entrecruzamento das linguagens verbal e visual. Uma das conclusões a que chegamos é a de que esse gênero textual, por se constituir de um sistema narrativo composto por duas semióticas que atuam em interação sincreticamente, tem na linguagem visual a sua principal fonte de transmissão, fazendo dele um autêntico 'megainstrumento' a ser mais estudado por todo aquele que se disponha a realizar 'transposição didática' (Chevellard, 1991).
\end{abstract}

Palavras-Chave: ISD, semiótica, gênero adaptação oficial de filme, sincretismo.

Recibido: 20-XI-2009 Aceptado: 24-V-2010
Correspondencia: Cláudia Lopes Nascimento Saito (cln_saito@yohoo.com.br). Departamento de Letras, Universidade Estadual Centro-Oeste. R. Salvatore Renna, Padre Salvador 875, Santa Cruz, Guarapuava-PR. CEP 85015-43, Brasil. 


\section{El género de 'adaptación' de la película cómica oficial}

Resumen: Con las mismas características de género de su origen -el cómic-, la 'adaptación oficial de la película cómica' ha ido en aumento por la presentación de la aplicación de películas cinematográficas para los medios impresos, por ejemplo, las películas de superhéroes como Spider-Man II, corpus de esta investigación. Tomando como marco teórico los fundamentos de la semiótica (Greimas $\&$ Courtés, 1979), junto con el interaccionismo sociodiscursivo (Bronckart, 2003, 2006), esta investigación presenta datos de análisis y descripción de la intersección de lenguaj es verbales y visuales. Una de las conclusiones a las que se llega es que este género textual, por constituirse de un sistema narrativo compuesto por dos semióticas interactuando sincréticamente, tiene en el lenguaje visual su principal fuente de transmisión, haciendo de él un auténtico 'megainstrumento' a ser más estudiado por cualquiera que esté dispuesto a hacer la 'transposición didáctica' (Chevallard, 1991).

Palabras Clave: ISD, semiótica, género de adaptación oficial de películas, sincretismo.

\section{The textual genre: The official adaptation of film to comic}

Abstract: Having the same characteristics of its genre of origin -the comic books-, official adaptations of films to comics have grown because they present the transposition of movies into printed matter, including the superhero (e.g., Spider-Man II) -the corpus of the present research. Based on the theoretical framework of both semiotics (Greimas \& Courtés, 1979) and sociodiscursive interactionism (Bronckart, 2003; 2006), this research presents data on the analysis and description of the intersection between verbal and visual languages. One of the conclusions is that -because this textual genre consists of a narrative system composed by two semiotics acting in syncretical interaction- it finds its main source in the visual language, thus making it an authentic and powerful tool to be studied by everyone who is willing to accomplish didactic transposition (Chevellard, 1991).

Key Words: SDI, semiotics, genre, official adaptation of film, syncretism.

\section{INTRODUÇÃO}

Na perspectiva do Interacionismo sociodiscursivo proposto por Bronckart (2006), entende-se a linguagem como um instrumento semiótico pelo qual o homem existe e age, o que implica interpretar os fatos de linguagem como "traços das condutas humanas socialmente contextualizadas" (Bronckart, 2006: 78).

Citado por Bronckart (2006) como uma das fontes teóricas do interacionismo sociodiscursivo, Bakhtin (1992) postula que os gêneros discursivos são construções sociais históricas como tudo o que é criado pelo homem e que, apesar de configurarem as ações humanas em qualquer contexto/ discurso: 
"Não são instrumentos estanques, enrijecedores da ação criativa do homem, são maleáveis, dinâmicos, transformam-se e se adaptam às necessidades e atividades sociais e culturais" (Bakhtin, 1992: 173).

Ao se referir a esse caráter mediador e vincular à concepção de gênero a de formas estáveis, Bakhtin (1992) demonstra ter previsto a velocidade que se impõe e interfere nas produções midiáticas.

As formulações bakhtinianas a respeito da constituição e funcionamento dos gêneros na comunicação verbal das diferentes esferas sociais refletem as tendências mais estáveis e perenes da evolução dos textos e antecipam as atividades de linguagem mediadas pelas modernas tecnologias.

\section{0 surgimento de um novo gênero}

Na relação dialógica entre os enunciados atuam 'forças centrípetas' que buscam a concentração, a centralização, a mesmice, e as 'forças centrífugas', que vão corroendo as tendências centralizadoras por meio de vários processos como a imitação, a paráfrase, a paródia, a estilização, a hibridização, em suma, a novidade.

Nesse jogo entre o velho e o novo, o que fica transparente é a idéia de que a produção e a interpretação de um texto estão atreladas ao reconhecimento de suas regularidades e variabilidades, o que faz com que um texto seja sempre construído dentro das convenções de um gênero. Como afirma Bakhtin (1992: 187), “onde há enunciado há gênero”, e o novo não significa necessariamente o inédito, mas novo porque é construído para uma ocasião social específica, para um momento sócio-histórico culturalmente determinado.

Se o princípio para a formação e diferenciação dos gêneros dentro das esferas sociais reside na finalidade da interação social e na relação entre os participantes e o objeto da interação, o gênero textual 'adaptação oficial de filme em quadrinhos' é um 'produto' que tem como finalidade promover o filme a partir da sua transposição da mídia cinematográfica para a impressa.

A adaptação oficial de filme em quadrinhos se apresenta, assim como todo gênero discursivo, como um enunciado 'relativamente estável' e como resultado da ação de um suj eito singular que, diante de determinados parâmetros da situação em que se encontrava, foi obrigado a (re) criar, transformar, enriquecer ou empobrecer um gênero que já existia antes como um artefato cultural e sócio-histórico, surgindo assim como um novo gênero.

Com as mesmas características do seu gênero de origem, as histórias em quadrinhos, o que vai 
diferenciar esse novo gênero (adaptação oficial de filme em quadrinhos) é que nele há um tema específico que são os filmes de super-heróis veiculados no cinema com sucesso de bilheteria. A adaptação, como o nome já indica, é a transposição de uma película cinematográfica para o suporte impresso 'gibi', com características temáticas, estilísticas e composicionais advindas das histórias em quadrinhos.

Isso poderia nos levar a pensar que se trata 'apenas' de uma variante de HQ, contudo assumimos que o gênero 'adaptação' se trata de um novo gênero por configurar uma atividade de linguagem em um contexto específico, com finalidades específicas e com características específicas. Assim, trata-se, ao nosso ver, de um novo gênero que conquistou seu espaço, sendo facilmente identificável visualmente, pois sua composição é bem estável.

No seu 'plano global textual' (Bronckart, 2003), podemos perceber que o formato do gibi é sempre o mesmo ( 26 por $17 \mathrm{~cm}$ ), a sua impressão é de altíssima qualidade, em sua capa sempre vem focalizada uma cena do filme em que aparece o super-herói; o nome do filme que foi adaptado para os quadrinhos, aparece na lateral esquerda, normalmente na parte superior da capa, a logomarca ou logotipo da produtora da HQ do super-herói se encontra no canto superior esquerdo; na parte inferior, centralizada, aparece a expressão 'adaptação oficial do filme' que vem, às vezes, acompanhada por outra expressão 'em quadrinhos'.

Com o intuito de caracterizar as especificidades centrais desse gênero discursivo, recorremos às adaptações oficiais de outros filmes de super-heróis, como ilustram as figuras abaixo, mas não esquecendo que estes exemplos são variantes do processo, uma vez que nosso interesse se dá apenas na adaptação do filme do Homem-Aranha II para os quadrinhos. 


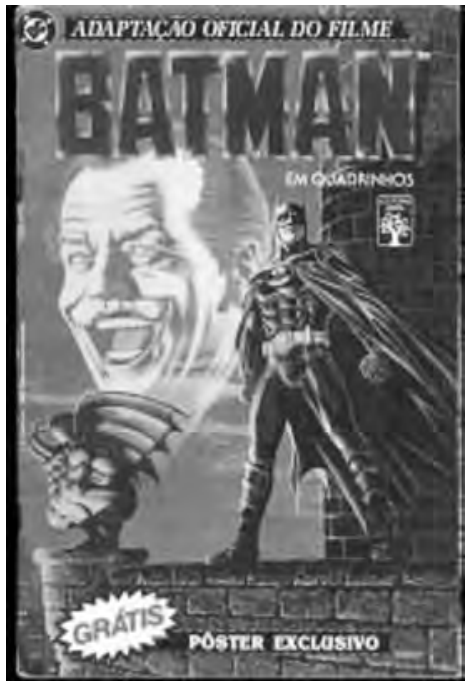

Ilustração 1. Adaptação Oficial do Filme Batman em Quadrinhos (1989).

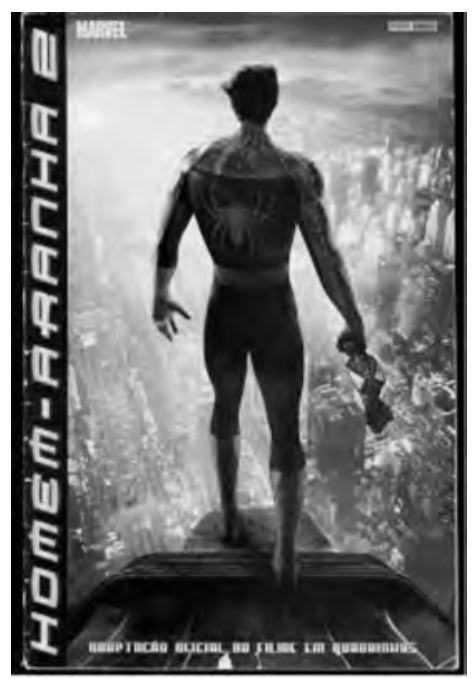

Ilustração 3. Adaptação Oficial do Filme Homem Aranha II em Quadrinhos (2004).

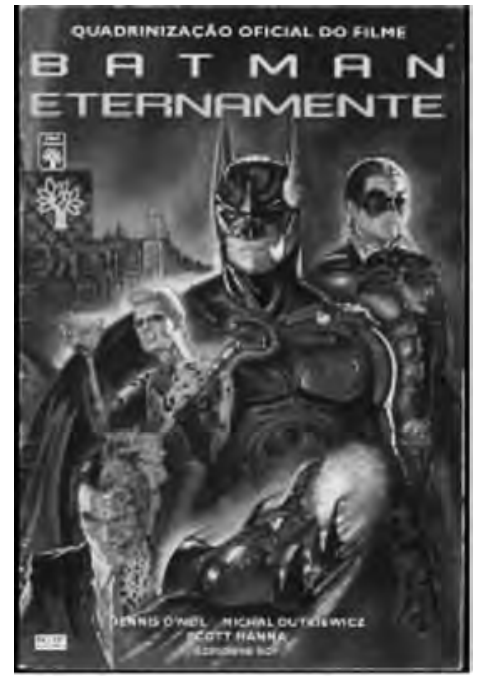

Ilustração 2. Quadrinização Oficial do Filme Batman Eternamente (1990).

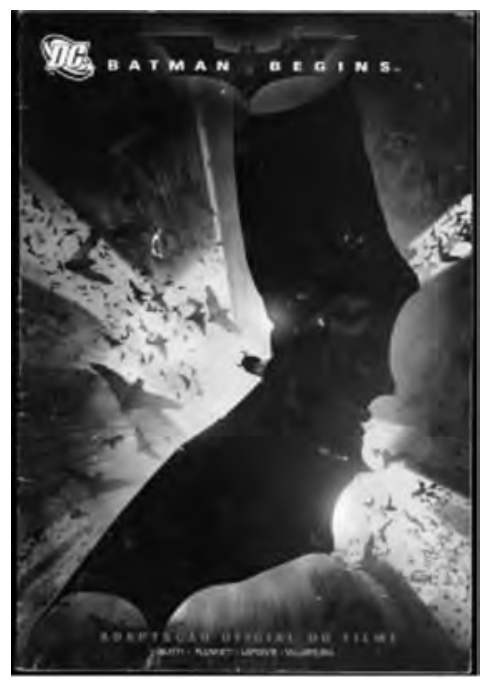

Ilustração 4. Adaptação Oficial do Filme Batman Begins em Quadrinhos (2005). 
$\mathrm{Na}$ antecapa, novamente vem em destaque o título do filme na parte superior e logo abaixo ao título são apresentadas indicações sobre o roteirista, o adaptador, o desenhista, o tradutor, os encarregados da arte final e das cores da adaptação, como também indicações dos nomes de todos aqueles envolvidos na produção cinematográfica. Na última página desta $\mathrm{HQ}$, novamente, aparecem informações sobre a equipe técnica da adaptação e do filme.

Como pudemos ver, um texto tende a ser inteiramente construído dentro das convenções de um gênero, por isso o novo não significa necessariamente o inédito. Portanto, o gênero 'adaptação' vai receber o mesmo tratamento que uma história em quadrinhos, uma vez que nos remete ao seu gênero-matriz.

Quanto ao 'mundo discursivo', ou seja, ao plano da enunciação e à operação psicológica em que se baseia (Bronckart, 2006) ${ }^{1}$, como a maioria das HQ, o gênero adaptação configura um discurso na ordem do narrar, apresentando um desvio forte em relação ao mundo ordinário da ação de linguagem, pois veicula um narrar totalmente ficcional, que corresponde ao arquétipo psicológico que Bronckart (2006) denomina de narração.

Dolz e Schneuwly (2004), autores afiliados à vertente mais didática do interacionsimo sociodiscursivo, buscaram contribuir para a construção de instrumentos que pudessem auxiliem o professor a planejar as atividades didáticas baseadas nas práticas de linguagem, apresentam uma proposta para o enfoque de agrupamentos de gêneros.

De acordo com a proposta dos autores, o gênero 'adaptação' pode ser incluído no 'agrupamento de gêneros' do narrar, tendo em vista os critérios apresentados pelos autores: 1 . quanto ao domínio social de comunicação, a adaptação é um gênero que pertence à cultura literária ficcional; 2. quanto às capacidades de linguagem dominantes, a adaptação se apresenta com um discurso da ordem do narrar em que se configura a mímeses da ação através da criação de intriga.

Além de 'tipo de discurso', para Bronckart (2003), outro elemento fundamental da infra-estrutura textual é a forma de organização sequencial ou linear dos textos. Considerando o discurso da ordem do narrar que predomina no gênero adaptação, outra características discursiva da adaptação é a predominância de seqüências narrativas e dialogais em sua constituição, apresentando uma linguagem verbal bem próxima da coloquial em sua modalidade oral, apoiada por uma linguagem não-verbal (visual).

\subsection{As condições de produção do gênero adaptação do filme}

Acrescentando mais um argumento que corrobora com a tese de que a 'adaptação oficial de 
filme em quadrinhos' constitui um novo gênero discursivo é que, na transposição de textos oriundos do cinema para os quadrinhos, podemos observar que as HQs têm uma narratividade mais peculiar se comparadas à mídia cinematográfica, uma vez que são mais condicionadas pelos aspectos pertinentes à sua linguagem, resultantes do ritmo e fluxo narrativos e pela decomposição, em segmentos seqüenciados, dos eventos presentes no enredo.

$\mathrm{Na}$ arte seqüencial, esses segmentos são os próprios quadrinhos, que encontram seus paralelos nas seqüências e planos da linguagem cinematográfica, não havendo, portanto, uma correspondência direta dos quadros das HQs com os quadros cinematográficos.

Os quadrinhos, por comporem um 'audiovisual impresso' que têm à disposição um espaço menor para exposição de imagens, têm capacidade e necessidade de sínteses maiores que o cinema, compondo-se numa linguagem que requer, além do texto escrito, que o próprio traço do desenho traga em si uma escritura, que tem por função se aproximar daquele do qual se originou.

A tradução², conforme Plaza (2001), é por definição criadora, pois mantém uma íntima relação com o original, mas trilha seu próprio caminho, gerando novas realidades, novas formas, novas imagens, novos conteúdos o que faz da adaptação a (re)criação de uma nova realidade.

No caso da adaptação do filme Homem-Aranha II, tradução interssemiótica em que focamos a nossa reflexão, embora o sujeito produtor da produção impressa tenha atropelado algumas passagens importantes da aventura cinematográfica, procurou ser o mais fiel possível. Certamente, deveria estar consciente de que construir uma história muito extensa iria, além de encarecer a sua produção, desviar o interesse da publicação, o que acabou sendo responsável pela simplificação do roteiro.

Outro fato importante a se considerar em relação às condições de produção desse gênero é que os quadrinhos não conseguem outorgar aos seus personagens qualidades interpretativas que acentuem determinados aspectos da personalidade, além daquilo que o próprio traço definiu de maneira geral.

Por isso, em alguns momentos, fora excluído completamente da versão em 'quadrinhos' o efeito dramático construído por Sam Raimi ao longo da produção cinematográfica e que o diferenciava dos demais filmes de super-heróis, caracterizando -o como sendo um longa- metragem de aventura com um tom dramático acentuado.

Nas telas de cinema, a construção do personagem é definida pelo diretor e mediada pelo autor, a partir de um quadro referente que orienta o que de fato se pretende extrair de determinadas situações e temas, constituindo-se, assim, a situação de produção do filme. 
Não podemos deixar de mencionar que as HQs são um desenho, portanto, não são uma "cópia fiel" da realidade. De acordo com Barthes (1982: 35):

"A operação do desenho (a codificação) obriga imediatamente uma certa partilha entre significante e insignificante: o desenho não reproduz tudo, e muitas vezes até bem poucas coisas, sem deixar, contudo de ser uma mensagem forte".

A história em quadrinhos veicula uma mensagem que se constitui a partir dos valores da cultura em que está inserida e promove um efeito de realidade, o que a torna passível de ser aceita como parte de nosso arcabouço sociocultural. Nesse caso, a concepção fica a cargo do desenhista e do escritor como conseqüência do seu 'olhar' interpretativo e avaliativo sobre o objeto, mas também dentro das possibilidades técnicas das quais dispõem.

Os desenhos, nas histórias em quadrinhos, têm um grafismo específico, que se notabilizam por terem que construir uma imagem num primeiro momento inanimada, congelada, que não ganha vida e movimento pela simples vontade do desenhista, mas, sim, quando percebida na ação receptiva do leitor. Isso implica em se reconhecer uma certa 'limitação' de ordem da continuidade nessa escritura quadrinhística que pode ser relacionada aos conceitos de corte, planos -imagem e planos- seqüência.

É o corte que opera e se familiariza muito mais com as obras filmadas -que é determinado, imposto e invariante à linguagem da $\mathrm{HQ}$ em suas qualidades intrínsecas, por sua própria natureza, visto que a cada quadro do desenho aparece obrigatoriamente realizado um corte, a chamada elipse.

Assim como fazem os elementos de corte cinematográficos, o desenhista precisa proporcionar ao leitor a continuidade fluida do enredo que tem em mãos e isso requer habilidade do 'suj eito-autor-criador', pois não podemos esquecer de que o gênero textual adaptação oficial é um "produto" que tem como finalidade promover o filme a partir da sua transposição para a mídia impressa.

\subsection{O homem-aranha: Um super-herói às avessas}

As primeiras aventuras envolvendo ficção científica apareceram no final da década de 20, pois até então as tiras publicadas pelos jornais tinham sempre um caráter humorístico. Com essas histórias de aventura veio também a tendência naturalista nos quadrinhos, que aproximou os desenhos de uma reprodução mais fiel de pessoas e objetos, ampliando o seu impacto junto ao público leitor.

Em 1960, é lançado o Homem-Aranha. Criado pelos americanos Stan Lee e Steve Ditko, esse 
super-herói surgiu quando Peter Parker, um adolescente americano, recebera uma picada de aranha radioativa. A partir desse acidente, o rapaz começou a ter super-poderes.

Apesar de sua criação como herói ser do tipo clássico, a carga de seus problemas pessoais nada tinha de tradicional, no que diz respeito aos quadrinhos. Esse super-herói nasceu com a marca dos tempos atuais, em que os super-heróis tornaram-se mais humanizados, passaram a refletir sobre suas angústias, medos e dúvidas.

Em sua identidade secreta, o Homem-Aranha se preocupa cotidianamente com problemas comuns de sobrevivência. Trabalhando para um jornal e morando em companhia de uma velha tia, com ele se identifica boa parte da classe média, vendo-o constantemente atrapalhado por causa de dinheiro, e sem que isso seja resolvido pelo fato de ser ele o Homem-Aranha, com poderes super humanos.

O Homem-Aranha que parece se caracterizar mais como um herói às avessas, um antípoda, vive no filme Homem-Aranha II uma grande crise existencial: ser ou não ser super-herói. Fato que nos influenciou e nos fez escolher a adaptação impressa desse filme como objeto de nossa pesquisa. Além de ter sido um sucesso de bilheteria, causou uma grande polêmica entre espectadores fanáticos pelo super-herói e, por isso, teve uma grande repercussão na imprensa dos países em que a película foi exibida.

Essa produção cinematográfica quebrou o paradigma de filmes de super-heróis: ao invés de apresentar muita ação como de costume, surpreendeu a todos quando dedicou praticamente metade do tempo de exibição da película a questões de cunho intimista.

\section{A adaptação impressa: Um gênero sincrético}

Dentre os sistemas visuais abrigados por pela adaptação impressa, a imagem, enquanto forma da expressão, é manifestada no papel por recortes chamados planos. Os enquadramentos ou planos, no sentido cinematográfico do termo, representam a forma como uma determinada imagem foi representada, limitada na altura e largura, da mesma forma como ocorre na pintura, na fotografia.

Os quadrinhos ora focados estão formatados em planos, tipos de cortes que se constituem em elementos de uma espécie de gramática de textualização e que podem ser entendidos como fatores determinantes da forma da expressão no caso da construção visual do texto. Os diversos planos são nomeados conforme se referirem à representação do corpo humano: plano geral; plano médio ou aproximado; plano americano; primeiro plano; plano de detalhe; pormenor ou close-up. 
Dessa forma, como que em câmera objetiva, aquela que assume posição do olho de um observador onipresente e onisciente, mas do ponto de vista de quem está fora da ação (no caso o destinatário), podemos mencionar os planos mais usados com frequiência na adaptação do filme do Homem-Aranha II.

Podemos observar que dos duzentos e setenta e um quadrinhos que compõem essa HQ, o modo de existência passional que caracteriza Peter Parker aparece reiterado em noventa e seis quadrinhos pelo imbricamento do visual com o verbal, tanto a expressão facial como corporal de Peter, mas também pelos os planos e ângulos utilizados pelo enunciador e que denunciam o estado de espírito do adolescente.

De todos os planos que compõem a organização visual desse gênero veiculado na mídia impressa, o plano médio é o mais utilizado por seu textualizador, pois enquadrando os atores da metade do tórax para cima, os diálogos entre os personagens são mais evidenciados, característica predominante do filme e, em conseqüência, da adaptação do filme Homem-Aranha II em quadrinhos.

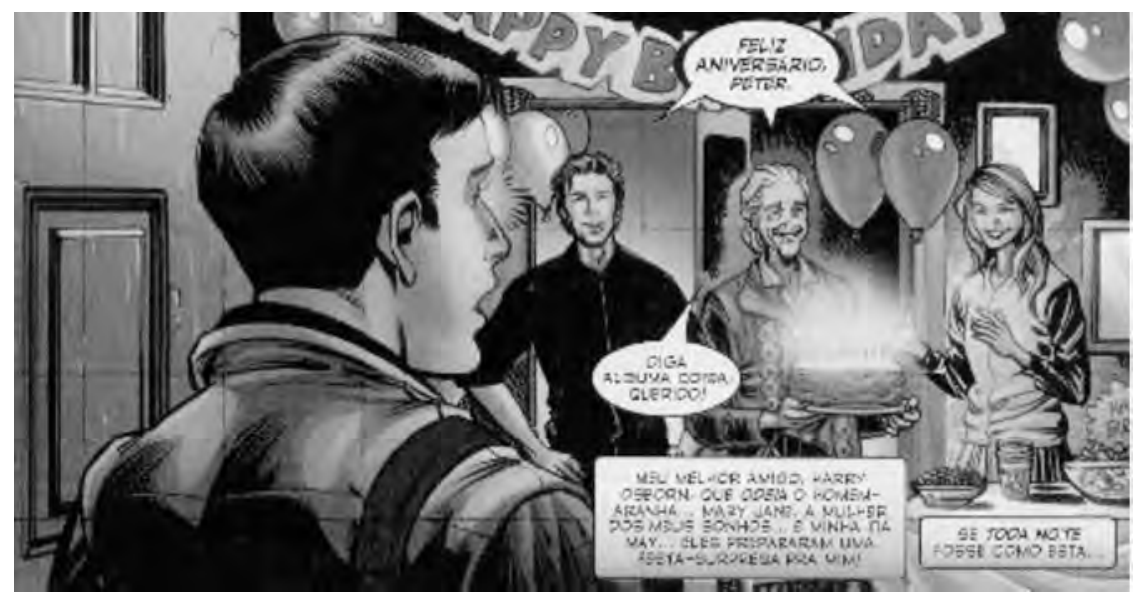

Ilustração 5. Adaptação Oficial do Filme Homem Aranha II em Quadrinhos (p. 5). 


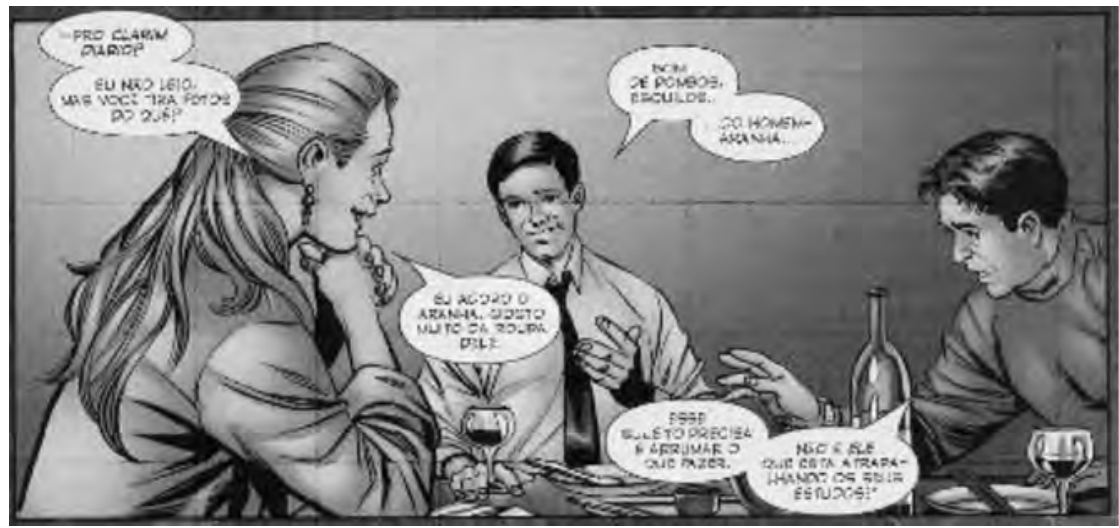

Ilustração 6. Adaptação Oficial do Filme Homem-Aranha II em quadrinhos (p. 10).

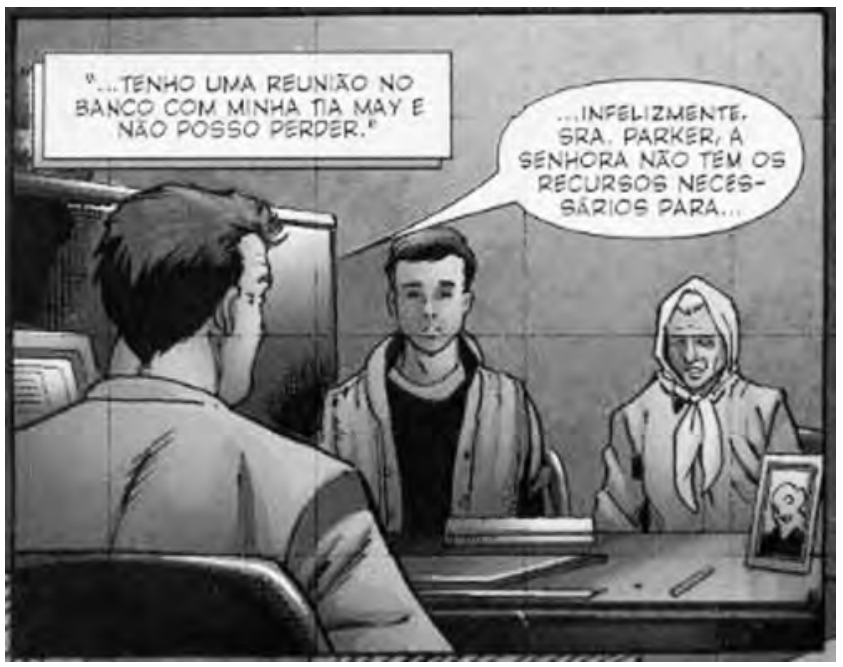

Ilustração 7. Adaptação Oficial do Filme Homem-Aranha II em quadrinhos (p. 10). 

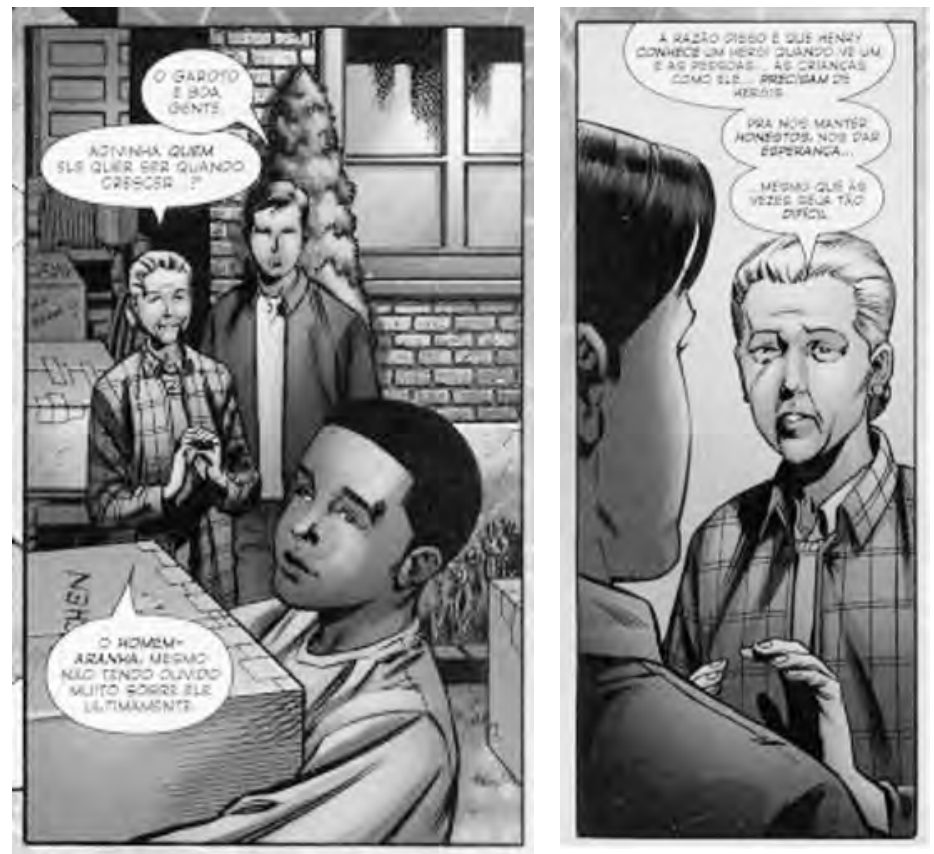

Ilustração 8. Adaptação Oficial do Filme Homem Aranha II em Quadrinhos (p. 35).

Percebemos que, em muitos quadrinhos, é utilizado o primeiro plano para tornarem nítidas as expressões faciais de Peter Parker e revelarem seus sentimentos com mais força dramática na tentativa de inserir o destinatário na 'alma' do personagem. Afinal, o que mais marcou essa aventura do Homem-Aranha foi a mescla de drama e ação: o fio condutor narrativo ao invés de ser utilizado apenas como pano de fundo para as cenas de luta entre o super-herói e seu inimigo Dr. Octopus, como normalmente acontece, foi ponto de destaque. 


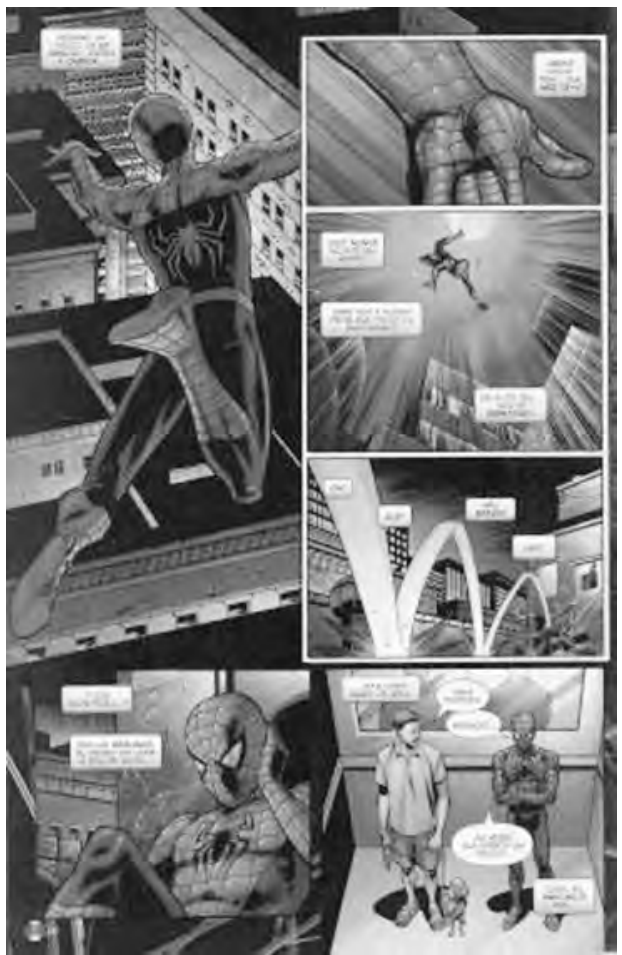

Ilustração 9. Adaptação Oficial do Filme Homem Aranha II em Quadrinhos (p. 28).

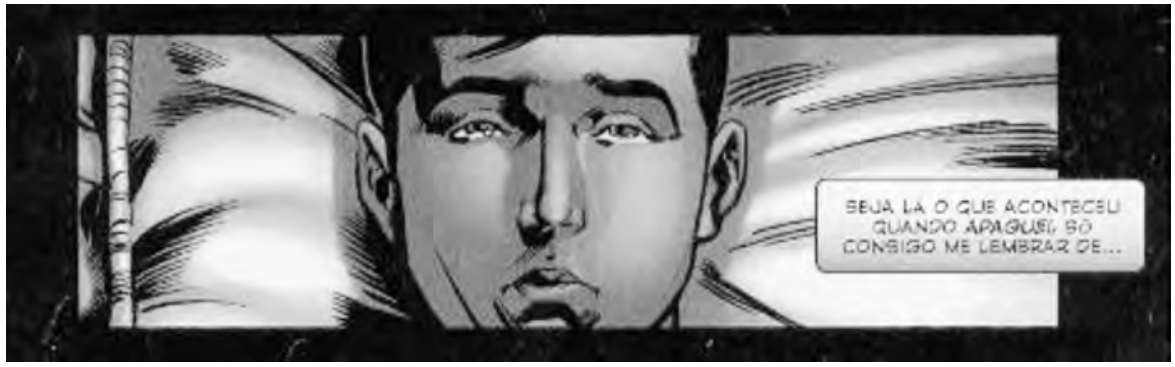

Ilustração 10. Adaptação Oficial do Filme Homem Aranha II em Quadrinhos (p. 41). 


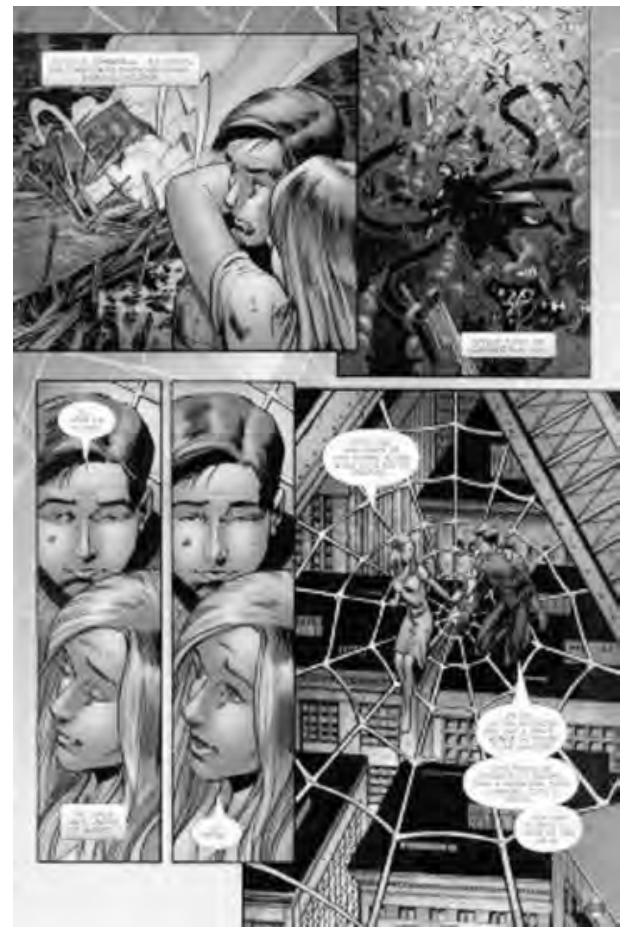

Ilustração 11. Adaptação Oficial do Filme Homem Aranha II em Quadrinhos (p. 47).

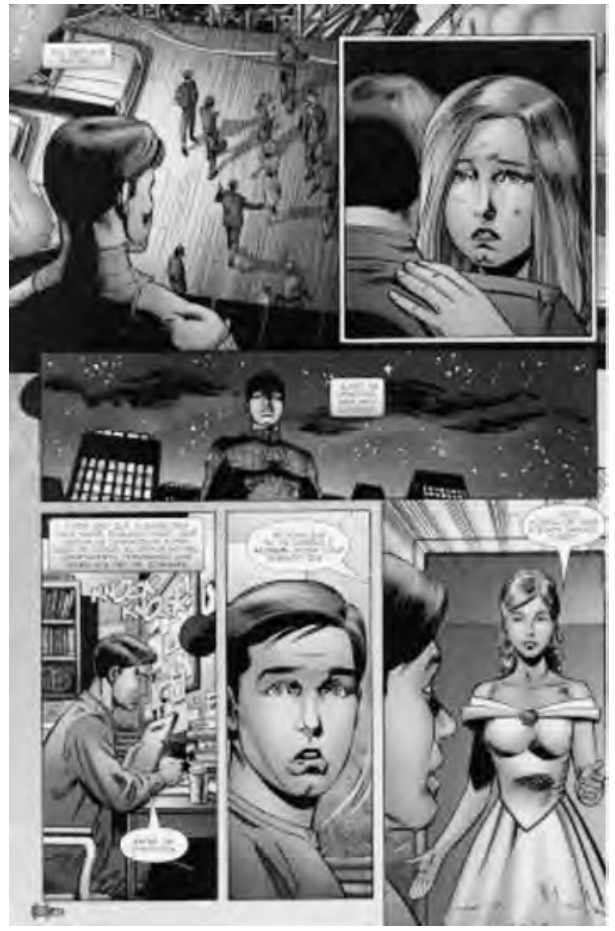

Ilustração 12. Adaptação Oficial do Filme Homem Aranha II em Quadrinhos (p. 48).

Na verdade, Peter Parker é o ator central, quase que exclusivo da narrativa; ocupa, assim, simultaneamente, inúmeras posições distintas. Destacado da ação, flutuando na incerteza, interroga-se sobre sua identidade, avalia e interpreta suas percepções, é um suj eito sensível e passional, já que experimenta dor, tristeza e indiferença.

Observando os quadrinhos da adaptação do filme Homem-Aranha II, em princípio destaca-se, pela maneira de se expressar e de agir, a figura de Peter -ator que se constitui pela não-alegria. Peter, o sujeito de busca de nossa narrativa, é marcado no enunciado pelo desânimo, tristeza e desolação.

Para enfatizar esse 'estado de alma' do rapaz, o narrador (textualizador) coloca no enunciado uma série de figuras de caráter somático -atitudes, gestos, proxêmica, expressão facial e cor- 


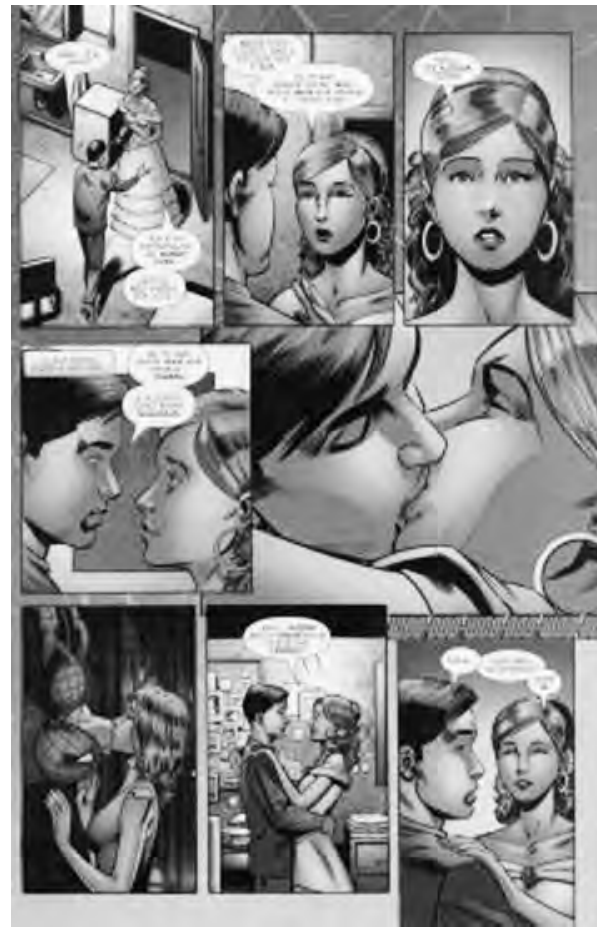

Ilustração 13. Adaptação Oficial do Filme Homem Aranha II em Quadrinhos (p. 49).

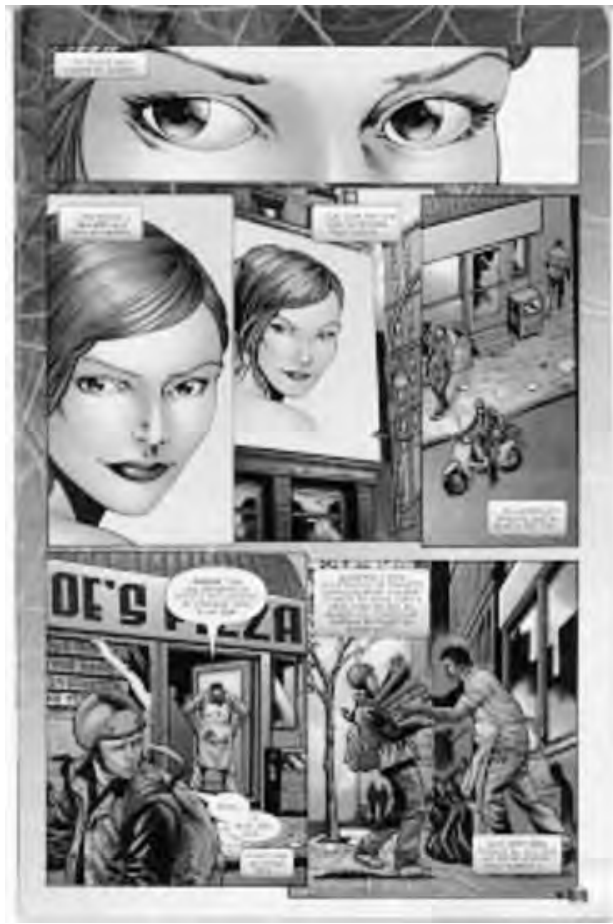

Ilustração 14. Adaptação Oficial do Filme Homem Aranha II em Quadrinhos (p. 3).

poral que, infelizmente, nos quadrinhos, fica menos visível que no cinema, mas que dão conta do processo de 'degradação emocional' provocado pela própria crise existencial pela qual passa o jovem no desenrolar da narrativa.

É a linguagem visual a serviço da verbal, utilizada a fim de se compor sincreticamente as características do sujeito passional Peter, que permanece em quase toda narrativa cabisbaixo, com os olhos semicerrados, a boca fechada ou arqueada para baixo e os ombros reclinados para frente na prostração do desânimo. Tal 'estado de alma' por se apresentar tão recorrente aponta para o seu modo de existência: um rapaz 'tenso' e 'infeliz'.

Como dissemos anteriormente, os quadrinhos constituem um sistema narrativo composto por duas semióticas que atuam em constante interação (sincreticamente): a visual e a verbal. Cada 
uma delas ocupa um papel especial, reforçando uma a outra e garantindo que o enunciado seja entendido em plenitude.

Entretanto, outros têm na linguagem visual a sua fonte de transmissão, como é o caso das projeções de pessoas no discurso que estão sincretizadas, principalmente, por outros sistemas produtores de significação, considerados secundários ou acessórios e que remetem a formas de linguagem conotativa e social, consideradas grandezas lingüísticas e pertencentes à gestualidade, à proxêmica que atuam diretamente como recursos de caracterização dos personagens.

Nas histórias em quadrinhos, apesar do texto estar aparentemente ancorado na linguagem escrita, os efeitos de sentido são constituídos e construídos pelas estratégias de enunciação, a partir das articulações entre as diferentes unidades dos sistemas de linguagens que aí engendram o sentido.

A característica de um enunciado discursivo como esse, em que se manifesta uma multiplicidade de sistemas, é tratada pelas chamadas semióticas sincréticas (Greimas, 1991). Essas abordam seus objetos de análise como um todo de significação e o sentido é construído pelas diferentes linguagens abrigadas e imbricadas no mesmo suporte. Essas articulações entre sistemas semióticos são responsáveis pela constituição do sentido produzido na HQ.

Na história da semiótica de Greimas (1991), segundo Barros (1986: 32):

"A necessidade de explicar os sistemas semióticos sincréticos, como o cinema, os quadrinhos ou a canção popular e a linguagem poética e plástica, levou os estudiosos a se voltarem para o plano da expressão".

As primeiras pesquisas com o discurso visual foram realizadas Lindekens (1968) no domínio da análise semiótica da imagem fotográfica. Anos mais tarde, em busca de um mesmo ideal vieram Floch $(1988,1990,1991,1995,1997)$ o Groupe $\mu$ (1992), e outros que deixaram uma grande contribuição à Semiótica do Visual.

Floch $(1988,1990,1991,1995,1997)$ empenhou-se em precisar a noção de sincretismo e estabelecer propostas de abordagem para os textos sincréticos. Para tanto, utilizou os pares conceituais forma/ substância e expressão/ conteúdo, desenvolvidos por Hjelmslev³ (1943) a partir de propostas de Saussure (1916).

Nessa linha, o autor definiu as semióticas sincréticas como aquelas em que o plano da expressão constitui-se de uma pluralidade de substâncias (por exemplo, sonora, visual, plástica), mas que possibilita a manifestação de uma forma única de linguagem (Floch, 1988).

Dessa forma, a sincretização resulta da presença de uma pluralidade de linguagens num contí- 
nuo discursivo, conforme as referências de Floch (1991), portanto, o enunciado não se separa em enunciações de diferentes naturezas, mas se manifesta acionado pelas várias linguagens.

Com suas pesquisas, Floch (1991) muito contribuiu para o campo da visualidade, pois agregou conhecimentos lingüísticos aos visuais, a fim de descrever os textos sincréticos em sua globalidade.

Por isso, quando partimos para o estudo dos mecanismos enunciativos utilizados pelo autor da adaptação impressa, devemos levar em consideração que, no gênero adaptação impressa, o significado se instaura por meio do imbricamento de diferentes sistemas de linguagem -o verbal e o imagético.

\section{Os mecanismos enunciativos}

Bronckart (2003) afirma que é na abordagem do nível dos mecanismos enunciativos que podemos reconhecer as operações de linguagem responsáveis pelo:

"Estabelecimento da coerência pragmática do texto [...] as avaliações que podem ser formuladas a respeito de um ou outro aspecto do conteúdo temático, assim como as instâncias que as assumem ou que se ‘responsabilizam’ por elas” (Bronckart, 2003: 319).

Podemos pensar que, nas histórias em quadrinhos, a responsabilidade das operações de linguagem não seja da competência exclusiva do autor empírico do texto, parece que a construção desse enunciado requer uma linha de produção formada por uma equipe enorme de profissionais.

$\mathrm{Na}$ antecapa da HQ vem a identificação dessas instâncias de responsabilidade: o autor, o roteirista, o adaptador, o desenhista (responsáveis pelas cores e pela arte final), assim como de todos aqueles envolvidos na produção. Isso em termos comerciais acrescenta valor ao que se veicula. Ao evidenciar os nomes de sucesso como o da Marvel, o da Columbia Pictures, por exemplo, a editora procura agregar qualidade e prestígio a seu produto.

Já no exame do gerenciamento das vozes enunciativas, devem ser observados alguns procedimentos discursivos ligados à delegação de voz e aos efeitos da enunciação decorrentes disso.

$\mathrm{Na}$ adaptação do filme do Homem-Aranha II, pela utilização do discurso em $1^{\text {a }}$ pessoa do singular, o narrador ${ }^{4}$ procura produzir um efeito de subjetividade em seu discurso, delegando a voz a Peter. Assim, do ponto de vista interno, ele assume o controle da narrativa, o dever e o poder narrar o discurso está em suas mãos. 
Peter Parker é ao mesmo tempo o suj eito explicitamente localizado da fala e o sujeito incerto de um discurso indireto livre. Ele, como sujeito da instância da enunciação simulada, ocupa o lugar de narrador, o que nos leva a pensar que há uma narrativa dentro de outra.

Nas HQs, a voz do narrador é apresentada em forma de legendas, que são dispostas normalmente no canto superior esquerdo e são destacadas ou não pela utilização de cores. No caso de nossa adaptação, as legendas aparecem assinaladas em azul, como podemos observar abaixo.

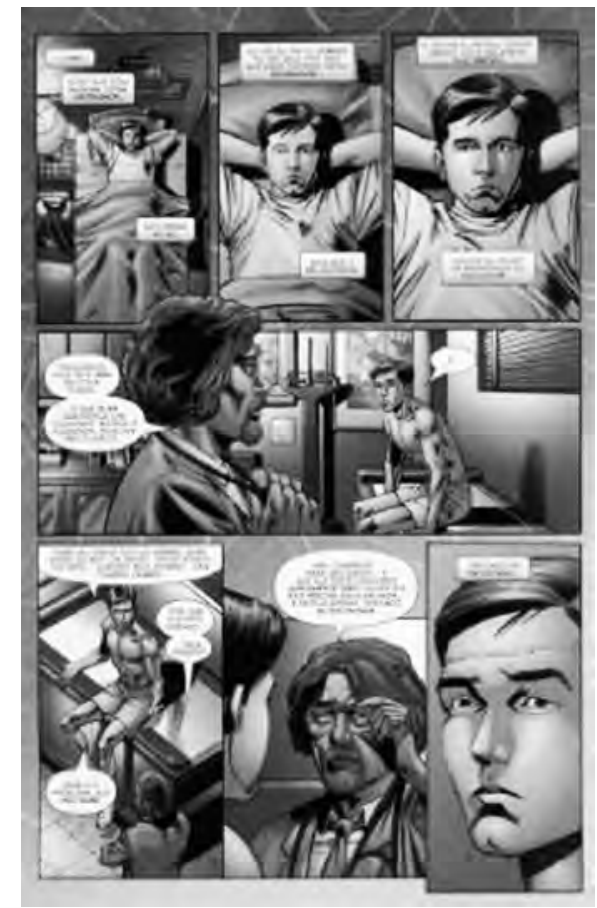

Ilustração 15. Adaptação Oficial do Filme Homem Aranha II em Quadrinhos (p. 29).

Essas legendas representam a voz de Peter e são utilizadas para nos situar no tempo e no espaço, indicando qualquer mudança de localização dos fatos, avanço ou retorno no fluxo temporal, assim como as expressões de sentimentos ou percepções dele.

Por sua vez, em relação às vozes enunciativas, percebemos que são gerenciadas pelo narrador 
que delegada voz aos personagens e simula o diálogo entre eles. No caso da adaptação do filme, essa delegação é realizada por meio dos balões, que não só representam que a palavra foi cedida aos interlocutores, mas também aumentam o efeito de verdade pretendido pelo narrador/ textualizador (Bronckart, 2003), uma vez que o discurso direto dá ao destinatário a ilusão de estar ouvindo o próprio discurso do 'outro', já que são bastante nítidas, até graficamente, as fronteiras entre o discurso do enunciador e o discurso do outro, pois uma voz não contamina a outra ${ }^{5}$.

\section{CONCLUSÕES}

Em nossa pesquisa concluímos que a 'adaptação oficial de filme em quadrinhos' trata-se de um novo gênero da mídia impressa, que surgiu da necessidade de se atrair aqueles que assistiram a um determinado filme de super-herói, mas que nem sempre tiveram o hábito de ler suas revistas em quadrinhos.

Com as mesmas características do seu gênero de origem, as histórias em quadrinhos, mas com um tema específico que são os filmes de super-heróis veiculados no cinema com sucesso de bilheteria, esse novo gênero consiste na transposição de uma película cinematográfica para o suporte impresso gibi.

Pudemos constatar que o trabalho com gêneros textuais verbo-visuais, como a adaptação do filme, impõe vários desafios ao analista, uma vez que implica na verificação de como os sentidos foram construídos a partir do imbricamento de vários sistemas de linguagem.

O limite entre a linguagem verbal e a visual se apresentou extremamente tênue em determinados momentos. Mesmo que lexicalizadas, as figuras do visual se fizeram imprescindíveis ao tentarmos analisar a construção da imagem do sujeito Peter Parker. 0 enunciador recorreu muito mais à linguagem visual, a fim de se compor sincreticamente o percurso do sujeito passional Peter, que propriamente à verbal.

Pudemos constatar, analisando os mecanismos enunciativos da adaptação, que a crise de identidade e os sentimentos passionais de Peter Parker são comedidos demais. 0 caráter demasiadamente humano, que esta aventura enfatiza, caracteriza-se pelo artificialismo e superficialismo, pois mesmo estando decepcionado, angustiado e aflito com a vida que leva Peter Parker não rompe com aquilo que Ihe foi tacitamente instituído: a missão de proteger a população de Nova York da ação de malfeitores. Acima de tudo, ele é um super-herói nos modelos clássicos, em que 0 'bom mocismo' deve prevalecer acima de qualquer coisa. 
Dessa análise, concluímos que, no nível do parecer (de leitura superficial), o filme HomemAranha II e, portanto, a adaptação para os quadrinhos constitui-se em uma nova proposta de aventura de ficção científica, envolvendo super-herói. Entretanto, em sua essência (de leitura mais profunda), constatamos que essa película e sua adaptação seguem os padrões clássicos das histórias em quadrinhos de super-heróis.

$\mathrm{Na}$ verdade, colocar em discurso valores e imagens que refletem a imagem daquele para quem se fala, dos valores em vigência na sociedade a que pertence, constitui nada mais que uma estratégia do textualizador.

Como sabemos, o autor faz escolhas ao construir seu enunciado sempre de acordo com as representações que faz de seu destinatário e os valores que quer colocar em discurso. Resgatar, então, em um texto, os valores que regem a dinâmica da vida social e determinam a 'práxis' sócio-cultural de um povo é, em certa medida, desvelar como os sujeitos se reconhecem e afirmam a própria identidade ${ }^{6}$.

\section{REFERÊNCIAS BIBLIOGRÁFICAS}

Bakhtin, M. (1992). Estética da criação verbal. São Paulo: Martins Fontes.

Barros, D. L. P. de. (1986). Texto e imagem. Linguagens -Revista da Regional Sul, 1, 29-38.

Barthes, R. (1982). Retórica da imagem. O óbvio e o obtuso. Lisboa: Edições 70.

Bronckart, J. P. (2003). Atividade de linguagem, textos e discursos. Por um interacionismo sócio-discursivo. São Paulo: EDUC.

Bronckart, J. P. (2006). Atividade de linguagem, discurso e desenvolvimento humano. Campinas: Mercado de Letras.

Chevellard, Y. (1991). La transposition didactique: Du savoir savant au savoir enseigné. Paris: Ed. La Fenseé Sauvage.

Dolz, J. \& Schneuwly, B. (2004). Gêneros e progressão em expressão oral e escrita: elementos para reflexão sobre uma experiência francófona. Em R. Rojo \& G. Sales Cordeiro (Trad.), Gêneros orais e escritos na escola (pp. 71-91). Campinas, SP: Mercado de Letras.

Floch, J. M. (1988). Quelques positions pour una sémiotique visuelle. Le Bulletin, Paris, Groupe de Recherches Sémio-Linguistiques, 1(4-5), 1-16.

Floch, J. M. (1990). Sémiotique, marketing et communication. Paris: Presses Universitaires de France.

Floch, J. M. (1991). Petites mythologies de I'oiel et l'espirit: Pour une sémiotique plastique. Paris: Hadés-Benjamins. 
Floch, J. M. (1995). Identités visuelles. Paris: Presses Universitaires de France.

Floch, J. M. (1997). Une lecture de tin tin au Tibet. Paris: Presses Universitaires de France.

Greimas, A. J. (1991). Semiótica figurativa e semiótica plástica. Significação-Revista Brasileira de Semiótica, Araraquara, 4, 18-46.

Greimas, A. J. \& Courtés, J. (1979). Dicionário de semiótica. São Paulo: Cultrix.

Groupe $\mu$ (1992). Traité du signe visuel. Paris: Seuil.

Hjelmslev, L. (1943). Prolégomènes à une théorie du langage. Paris: Minuit.

Plaza, J . (2001). Tradução intersemiótica. São Paulo: Perspectiva; Brasília: CNPq.

Saussure, F. (1975). Curso de lingüística geral. São Paulo: Cultrix.

\section{Fonte das ilustrações}

Homem Aranha II: Adaptação oficial do filme em quadrinhos (2004). Barueri/ SP, Marvel / Panini Comics.

\section{NOTAS}

1 A discussão sobre 'gêneros textuais' e 'tipos de discurso' pode ser conferida em Bronckart (2006: 121-160). 0 autor se refere a essas duas 'etiquetas' como "propiciadoras de desenvolvimento", ao enfatizar a importância da análise das características do agir não verbal (agir geral) ao agir de linguagem pelo ângulo das atividades de linguagem, realização que se dá sob a forma de textos que se diversificam em 'espécies'. Assim, o autor faz a opção de reservar a noção de gênero somente aos textos -'gêneros de texto/ gêneros textuais' utilizando, em outros níveis, as fórmulas "espécies de atividades de linguagem", ou "espécies de discurso".

2 Nesse particular, além dos recursos do texto e imagem, o cinema conta com o movimento, com a ação direta de seus personagens, o que Ihe permite maior exploração das estruturas de imagem. Assim, a escritura significada pela tela torna-se bem menos dependente do textual, do verbal.

3 Hjelmslev definiu o signo como sendo a conjunção da forma de expressão com a forma do conteúdo -denominada semiose ou função semiótica. Os estudos do professor dinamarquês coincidem com a linha de pesquisa de seu colega suíço, Saussure, que encontrava no signo uma relação de pressuposição recíproca entre o significante e o significado. Entretanto, a sua grande inovação foi dissociar os dois planos da linguagem (expressão vs conteúdo). A dicotomia expressão/ conteúdo foi utilizada por Hjelmslev para distinguir os dois planos da linguagem, seguindo 0 pensamento saussureano que definira o signo como a combinação de um significado (conceito) e um significante (imagem acústica). Expressão e conteúdo são, portanto, análogos aos conceitos de significante e significado: é a reunião desses dois planos da linguagem que permite explicar a existência de enunciados providos de sentido (Greimas \& Courtés, 1979). A dicotomia forma/ substância, empregada por Saussure a fim de distinguir a estrutura significante (por exemplo, a 
língua) da realidade semântica ou material (por exemplo, os sons), em que a língua se projeta, foi empregada por Hjelmslev, que a ampliou aos dois planos da linguagem (expressão/ conteúdo), com o que distinguiu quatro categorias: substância da expressão e forma da expressão, substância do conteúdo e forma do conteúdo.

4 Recorrendo ao procedimento analítico de Bronckart (2003) ao se referir às instâncias enunciativas o autor considera as instâncias do autor, do narrador e das vozes enunciativas, estas definidas como as entidades que assumem, ou às quais são atribuídas a responsabilidade do que é enunciado.

5 Os balões também fazem a vez dos verbos de elocução da linguagem verbal, servem para caracterizar outra semiótica presente -os elementos relativos à oralidade (elocução, entoação, intensidade da voz, etc). Os balões são o resultado de uma convenção no seio da linguagem das HQs, o continente do balão, ou seja, a linha que o delimita, também informa várias coisas ao leitor: Por exemplo, as linhas tracejadas transmitem a idéia de que 0 personagem está falando em voz baixa.

6 Tanto o filme como sua adaptação impressa são considerados como um produto da indústria cultural de massa que, enquanto artefatos midiáticos, são capazes de gerar bens simbólicos que permeiam o imaginário social. Bronckart (2003: 322), “[...] a ação de linguagem se traduz por uma 'reposição em circulação', no campo das representações sociais cristalizadas no intertexto, de representações já dialógicas, que têm sua sede no autor. Esse confronto das representações pessoais com as representações dos outros não pode se efetuar apenas no 'espaço mental' do autor: ele exige a criação de um espaço mental comum ou coletivo". 